\title{
A New Computerized System for Tree Ring Measurement and Analysis
}

by

\author{
Merlise A. Clyde ${ }^{1}$ and Stephen J. Titus ${ }^{2}$
}

\begin{abstract}
The Tree Ring Measurement System provides a relatively inexpensive, accurate, and efficient method of measuring diameter increments on cores or stem analysis disks while eliminating data recording and keypunching errors. The system consists of a microscope, sample positioning mechanism with optical encoder, and IBM PC/XT/AT microcomputer. The interactive menu-driven Fortran program displays diameter increments during data acquisition, and allows data to be plotted, edited, displayed, or remeasured at any time. The software can be modified to meet the user's requirements.
\end{abstract}

\begin{abstract}
Résumé
Le système de mesure des anneaux de croissance procure une méthode relativement peu coûteuse, précise et efficiente de mesure des accroissements en diamêtre à partir des carottes ou des rondelles d'analyse des tiges, tout en éliminant les erreurs d'enregistrement et de poinçonnage des données. Le système consiste en un microscope, un mécanisme de positionnement de l'échantillon muni d'un encodeur optique et d'un micro-ordinateur IBM PC/XT/AT. Le programme interactif à base de menus et rédigé en Fortran illustre les accroissements en diamêtre lors de la lecture des données, et permet aux données d'être transposées sous forme de graphique, d'être retransposées et illustrées de nouveau, ou remesurées à tout moment. Le logiciel peut être adapté aux besoins de l'utilisateur.
\end{abstract}

\section{Introduction}

Accurate measurement of diameter increments from stem analysis or increment cores is important for reconstructing the past growth and development of trees for dendrochronology and growth and yield studies. Undertaking such a task manually is time consuming and can result in errors at several stages of the measurement process. By using a computerized system for measuring diameter increment, data recording and keypunching errors can be eliminated, and measurement accuracy and precision can be improved.

In currently available automated systems, such as the Addo-X or Digi-Mic, examination and analysis of data are not easily done during the measuring stage. (See Bains and Micko [1985] for a comparison of the two systems.) This lag between data measurement and editing makes error detection and correction more difficult. Fayle et al. (1983) and Jordan and Ballance (1983) have developed software to connect Apple and Radioshack microcomputers to the Digi-Mic. The interactive software of Fayle et al. provides a means of editing and plotting tree ring data while measuring with the Digi-Mic. Fayle et al. also discuss development of an inexpensive

1Department of Statistics, University of California, Riverside, California 92521. 2Department of Forest Science, University of Alberta, Edmonton, Alberta T6G $2 \mathrm{H} 1$
Apple-based measuring system using the Sony Magnascale electronic ruler. However, we are unaware of any published reports of software and measuring devices that have been designed for IBM or IBM-compatible microcomputers. Thus, the Tree Ring Measurement System provides an inexpensive alternative to the Digi-Mic and Addo-X measuring systems and flexible software to control measuring, editing, and plotting that can be used with an IBM PC/XT/AT microcomputer.

\section{Description of System}

The Tree Ring Measurement System consists of a boom binocular microscope, positioning mechanism, and an IBM $\mathrm{PC} / \mathrm{XT} / \mathrm{AT}$ microcomputer system (Figure 1). Minimum configuration of the microcomputer requires two disk drives, $512 \mathrm{~K}$ memory and a math-coprocessor. The positioning Ballance (1983) have developed software to connect Apple and Radioshack microcomputers to the Digi-Mic. The interactive software of Fayle et al. provides a means of editing and plotting tree ring data while measuring with the Digi-Mic. Fayle et al. also discuss development of an inexpensive Apple-based measuring system using the Sony Magnascale electronic ruler. However, we are unaware of any published reports of software and measuring devicẹs that have been designed for IBM or IBM-compatible microcomputers. Thus, the Tree Ring Measurement System provides an inexpensive alternative to the Digi-Mic and Addo- $X$ measuring systems 


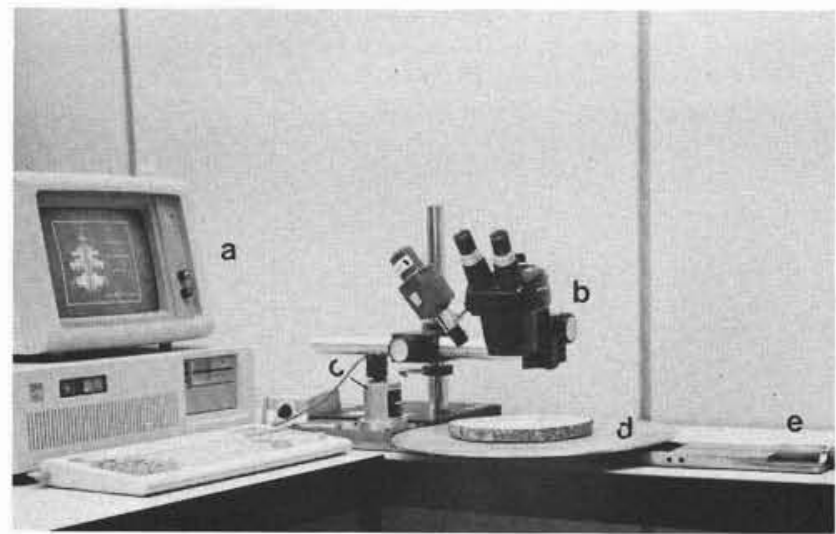

Figure 1. Tree Ring Measurement System: (a) IBM microcomputer system, (b) boom microscope, (c-e) positioning mechanism: (c) BEl optical encoder, (d) measuring platform, and (e) thumb-wheel

and flexible software to control measuring, editing, and plotting that can be used with an IBM PC/XT/AT microcomputer.

\section{Description of System}

The Tree Ring Measurement System consists of a boom binocular microscope, positioning mechanism, and an IBM $\mathrm{PC} / \mathrm{XT} / \mathrm{AT}$ microcomputer system (Figure 1). Minimum configuration of the microcomputer requires two disk drives, $512 \mathrm{~K}$ memory and a math-coprocessor. The positioning mechanism controls movement of the core or disk under the microscope and can be fitted with a platter for disks or an increment core holder. Either the platter or core holder can be mounted on a swivel base so that measurements can be made perpendicular to each growth ring. Movement of the sample is accomplished by the operator turning the thumbwheel while viewing the sample through the microscope. Pressing the appropriate function key as shown in the measurement menu on the screen denotes the end of a ring. The operator can then measure the next ring or back up by turning the thumb-wheel the opposite direction and remeasure the previous ring(s). Although the movement of the sample is not automatic as in the Digi-Mic, measurement speed is comparable (Timmer and Verch 1983). Approximately 12 radii ( 90 years old, $18 \mathrm{~cm}$ long) can be measured per hour. In general, measurement time depends on the average ring width, sample preparation, and microscope quality.

\section{Software Features}

Unlike other measurement systems, measurement control originates with the microcomputer's software. The program is written in IBM Professional Fortran, with Fortran callable Assembly Language subroutines for reading distances from the measuring device, since Fortran does not have facilities to read from input ports. All commands are displayed in a menu with options selected by pressing the appropriate function key or as a prompt with input from the keyboard. The program uses the IBM Graphics Development Toolkit and Virtual Device Interface (VDI) device drivers for screen displays, so the program can be easily used with different monitors.

The operator can specify the direction of measurement, either from center to bark, or from bark to center. During data acquisition, radial growth increments and corresponding ages are displayed on the screen. The program allows measurement of a maximum of four radii per section, and will test whether ages of all radii in a section are equal. If different radii in a section do not have the same age, the complete radii or portions thereof can then be remeasured immediately or later to locate and correct the error.

The program is currently designed to automatically merge the radial growth measurements into an existing stem analysis data file, containing heights to each section and other tree or plot characteristics, as the data is measured. The data can be displayed on the screen or printed on a printer by individual sections or for the entire tree. The data can also be plotted in several types of graphs on a dot matrix printer, pen plotter, laser printer, or displayed on the screen if a color/ graphics adapter is installed in the microcomputer. We used Plot88 (Plotworks Inc., La Jolla, California) Fortran callable subroutines for all graphs. Plots of ring widths all formed in the same year versus height (a Duff and Nolan [1953] Type 1 sequence; Figure 2) and ring widths at a given height versus age (a Duff and Nolan [1953] Type 2 sequence; Figure 3) can be generated, as well as cumulative height-age curve (Figure 4), stem taper at various ages (Figure 5), and threedimensional representation of diameter increment, age, and height (Figure 6). Quality of the graphs depends on the output device selected. Figures 2 to 5 were produced with a Hewlett Packard Laserjet printer at medium resolution. Figure 6 was produced on the same printer but at low resolution. Quality of the graph in Figure 6 is comparable to output from an inexpensive dot matrix printer. Better resolution can be obtained by using a pen plotter.

Plotting the data provides a way of detecting measurement errors, and can aid interpretation of the data. Although at first glance the plot of diameter increment, height, and age (Figure 6) appears to be quite complicated, it does provide some interesting insights into the growth and development of a tree. By taking "slices" from the surface parallel to the height axis, holding age constant, one can obtain a Duff and Nolan Type 1 sequence (Figure 2). By slicing the surface parallel to the age axis, one obtains a Duff and Nolan Type 2 sequence (Figure 3). One can also see that during certain years conditions were not as favorable for diameter growth causing "troughs" running parallel to the height axis. Likewise, one can also see "ridges" that formed when conditions were better. Another interesting aspect is that the maximum diameter increment at each height steadily declines with age. The age at which the maximum diameter at each height occurs tends to parallel that of the cumulative height-age curve.

\section{System Mechanics}

The microcomputer is connected to a BEI optical incremental encoder ${ }^{3}$ which is coupled to the base of the positioning mechanism by a rack and anti-backlash gear. Incremental analog-to-digital encoders are devices for measuring movement of a mechanical input. Rotation of the shaft of the optical encoder by turning the thumb-wheel causes a sensing of motion and direction, with output in the form of digital voltage levels. Since the direction is indicated electronically by the optical encoder, the computer circuitry

3The BEI LED optical encoder model 5VL79D-4 is available from BEI
Electronics, Inc., 1101 McAlmont, P.O. Box 3838, Little Rock. Arkansas, USA Electronics, Inc., 1101 McAlmont,
72203. Phone: (501) 372-7351. 
can count the pulses in either direction with an up-down counter ${ }^{4}$. The accumulated "counts" can then be translated into the distance the sample has moved.

PLOT $=$ 000127. TREE $=03$

\section{RING WIDTH us HEIGHT}

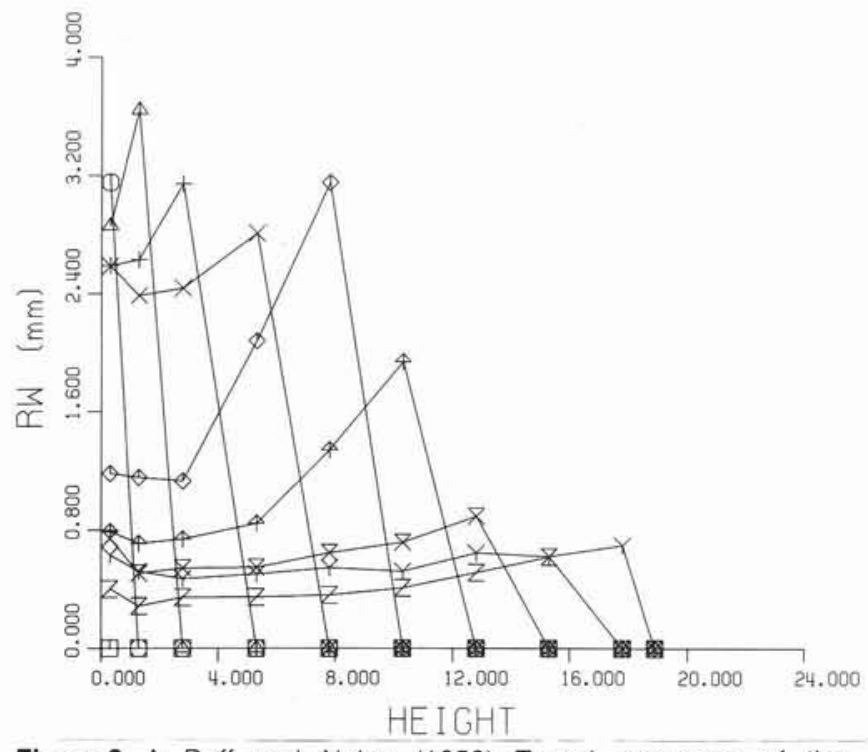

Figure 2. A Duff and Nolan (1953) Type 1 sequence of the longitudinal distribution of annual radial increment. Plot of ring widths all formed during the same year versus height.

$$
\text { PLOT }=000127, \text { TREE }=03, \text { SEC }=05
$$

$$
\text { RING WIDTH us AGE }
$$

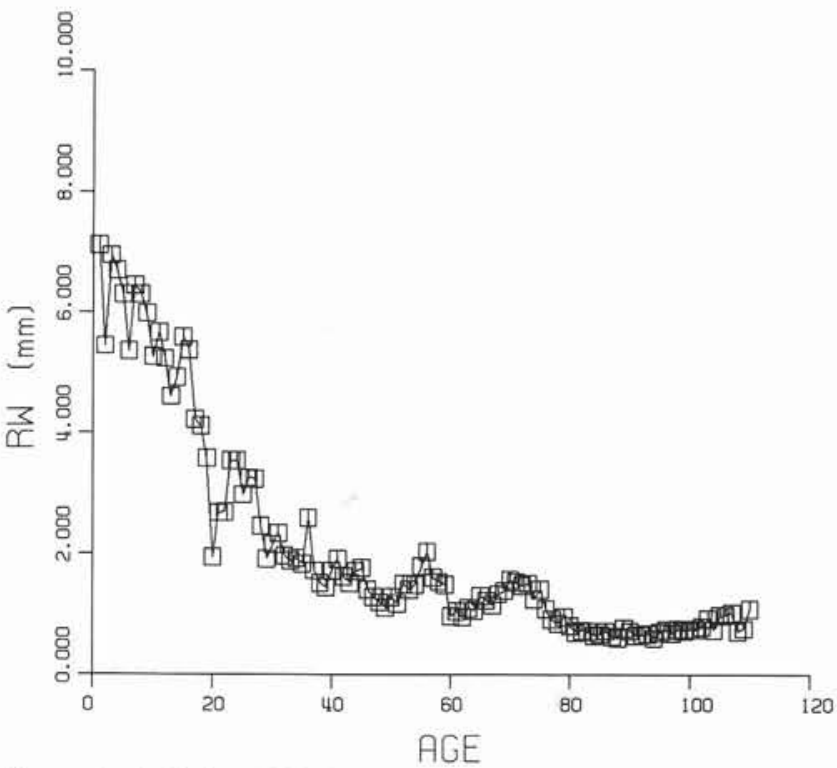

Figure 3. A Duff and Nolan (1953) Type 2 sequence. Plot of ring widths all formed at the same height versus the number of years from formation.

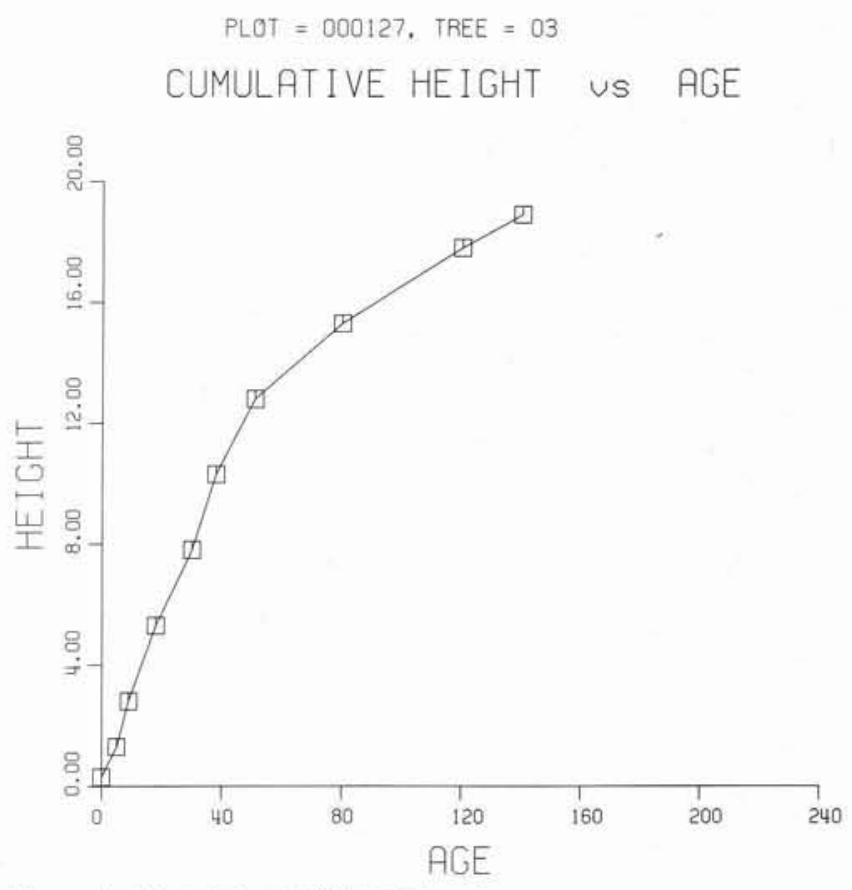

Figure 4. Cumulative height-age curve.

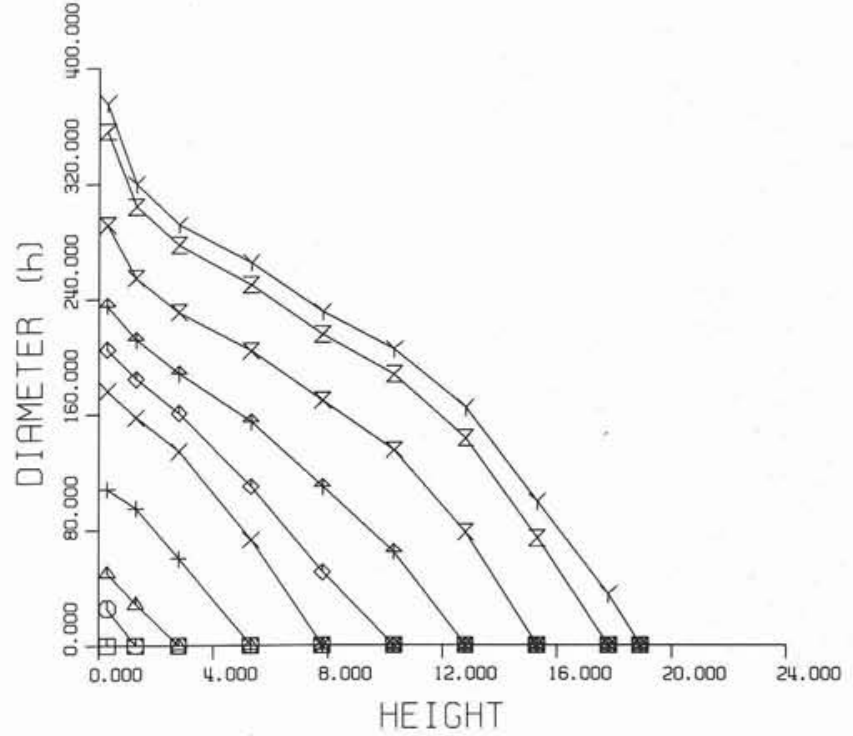

Figure 5. Plot of stem taper for various ages of the tree. ${ }^{4 A}$ microcomputer board could not be obtained commercially with an up-down
counter and 5-volt power supply for the optical encoder. The up-down counter
board was built by Technical Services at the University of Alberta. Schematic
diagrams of the board and positioning mechanism are available from the authors. 
PLOT $=$ O00127. TREE $=03$

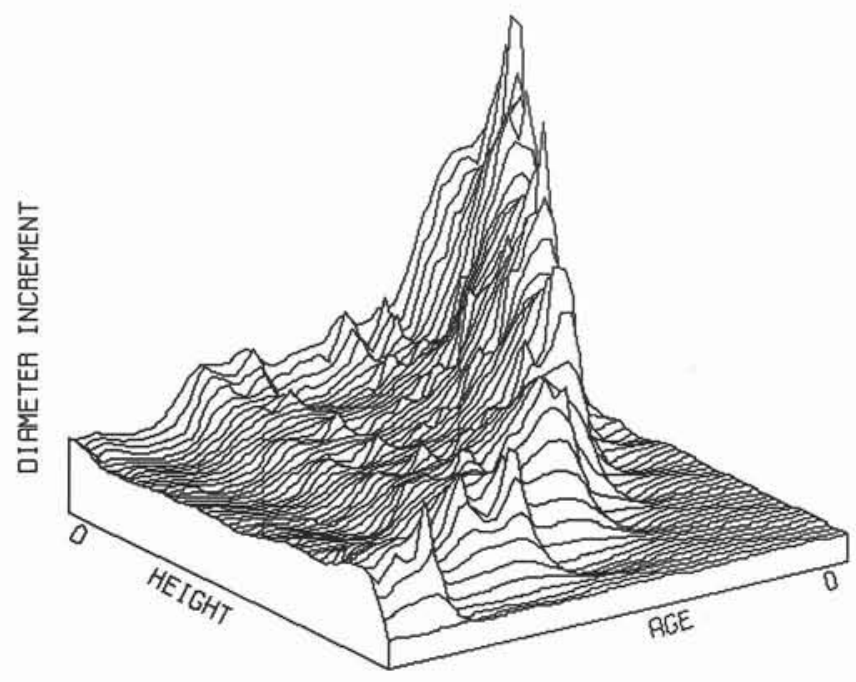

HEIGHT-AGE-DIAMETER INCREMENT

Figure 6. Three-dimensional representation of diameter increment, height, and age for one tree.

\section{Accuracy}

Because distance is determined from electronic pulses, and the counter is incremented only after a complete pulse is generated, a small measurement error results from the computer's inability to count a fraction of a pulse. The counter is reset after every measurement so that errors do not accumulate, limiting the maximum error associated with each measurement to the distance per count. Based on the mechanics of the system, there are 133 counts per millimetre or $0.00752 \mathrm{~mm} / \mathrm{count}$, which represents the intrinsic accuracy of the system. A Linear Variable Differential Transformer (LVDT) was used for empirically determining the accuracy of the system (Herceg 1976). LVDT's are very accurate instruments for electronic measurement (in millivolts $[\mathrm{mV}])$ of displacement of an object. The LVDT used was approximately three times as accurate as the optical encoder. For the LVDT, there is constant relationship between $\mathrm{mV}$ and distance. For calibrating the measuring device, the thumbwheel was turned for a fixed number of counts and the displacement in $\mathrm{mV}$ was read from the LVDT. This was used in verifying the relationship between counts and distance. Based on 50 measurements over a range from 125 to 145 counts, the optical encoder outputs one pulse per $0.00746 \pm$ $0.000230 \mathrm{~mm}$ (values are mean \pm one standard deviation). The $0.00752 \mathrm{~mm} /$ count based on the mechanics of the system falls within this interval.

Because the maximum error of the encoder will be less than the distance associated with one count, the maximum absolute error will be constant for all distances measured $(0.00752 \mathrm{~mm})$. However, as the distance measured increases, the maximum relative error will decrease. On average, the maximum relative error for a $0.1 \mathrm{~mm}$ distance would be less than $7.5 \%$. For distances greater than $1.0 \mathrm{~mm}$, the maximum relative error will be less than $0.75 \%$. On average, the error will be smaller, as evidenced by the value of the standard deviation, which includes the error associated with the operator, optical encoder, and any mechanical errors in the system. Sample preparation, microscope quality, and operator use will have a greater impact on measurement errors. The Digi-Mic and Addo-X are reported to be accurate to $0.01 \mathrm{~mm}$.

We do not have any data showing the effect of operator experience, operating environment, or measurement speed on accuracy and precision. The operator controls measurement speed through the thumb-wheel. Because the code for reading data from the counter is written in Assembly Language, there is no problem with the computer keeping up with the measurements. Likewise, we have not encountered any problems with measurements made at slow speeds. Because the program is interactive, it is fairly easy for an inexperienced operator to use. The different options in the measuring menu allow the operator to remeasure rings at any time so that errors can be easily corrected.

\section{Discussion}

The Tree Ring Measurement System is a self-contained, automated system for measuring radial growth increments. One of the main advantages of the system is its cost: excluding the microcomputer and microscope, the measuring device can be put together for under $\$ 1500$ Can., a fraction of the cost of other systems, while maintaining accuracy. Because of the current software license agreements from Plotworks and IBM for plotting subroutines included in the program and the VDI device drivers used to run the program on different monitors, the compiled version of the program cannot be distributed. Purchase of the additional software (IBM Professional Fortran, IBM Graphics Development Toolkit, and Plotworks Plot88) would add another $\$ 1500 \mathrm{Can}$. to the cost. The Digi-Mic includes a cassette recorder and RS232 interface for data transfer and is available for $\$ 11950$ Can., without a microcomputer, microscope, or software.

Another advantage of the system is its flexibility. Data are available in a usable form on the microcomputer for additional analyses and can be stored in any format, unlike the prespecified format of the Addo-X or Digi-Mic. Data are recorded on paper tape for the Addo-X, and onto cassette for the DigiMic, although modifications by Fayle et al. (1983) and Jordan and Ballance (1983) permit data from the Digi-Mic to be stored directly on computer diskettes.

The program includes plotting facilities for graphs comparable to those produced with a program developed by Timmer and Verch (1983) for mainframe computers using data generated by the Digi-Mic. The user can modify the program source code to substitute other plotting and editing routines or customize the software to their needs. Because of difficulty in bringing stem analysis disks back from the field, the system could be modified to measure growth rings from photographs of the sections (Biging and Wensel 1984) and scale the distances accordingly. However, this method would not be appropriate in cases where the radial increment is quite small, since the photograph would not show the necessary detail. Since many organizations have IBM or IBM compatible microcomputers and statistical software, this system provides an alternative to previously developed systems for Apple and Radioshack computers using the more expensive Digi-Mic. Additional information on hardware and software for the system may be obtained by writing to the authors. Copies of the source code are available (diskette or printed listing) for a small handling charge. 


\section{Acknowledgments}

The authors would like to thank Dwight Kruger for programming contributions and Jack Campbell for use of the measuring device and optical encoder. This research was supported by a grant from the Alberta Forest Development Research Trust.

\section{References}

Bains, B.S. and M.M. Micko. 1985. Computerization of tree growth measurement in the wood quality laboratory - improvement and modification of two systems. Univ. Alberta Agric. and For Bul. 8(1): 63-66

Biging, G.S. and L.C. Wensel. 1984. A photographic technique for use with stem analysis. For. Sci. 30: 715-729.
Duff, G.H. and N.J. Nolan. 1953. Growth and morphogenesis in the Canadian forest species. I. The controls of cambial and apical activity in Pinus resinosa Ait. Can. J. Bot. 31: 471-513

Fayle, D.C.F., D. Maclver and C.V. Bentley. 1983. Computergraphing of annual ring widths during measurement. For. Chron. 59: 291-293.

Herceg, E.E. 1976. Handbook of Measurement and Control. Schaevitz Engineering. Pennsauken, New Jersey.

Jordan, G.A. and R.H. Ballance. 1983. A microcomputer-based annual ring measurement system. For. Chron. 59:21-25.

Timmer, V.R. and B.R. Verch. 1983. SAPP: A computer program for plotting stem analysis. For. Chron. 59: 298-303.

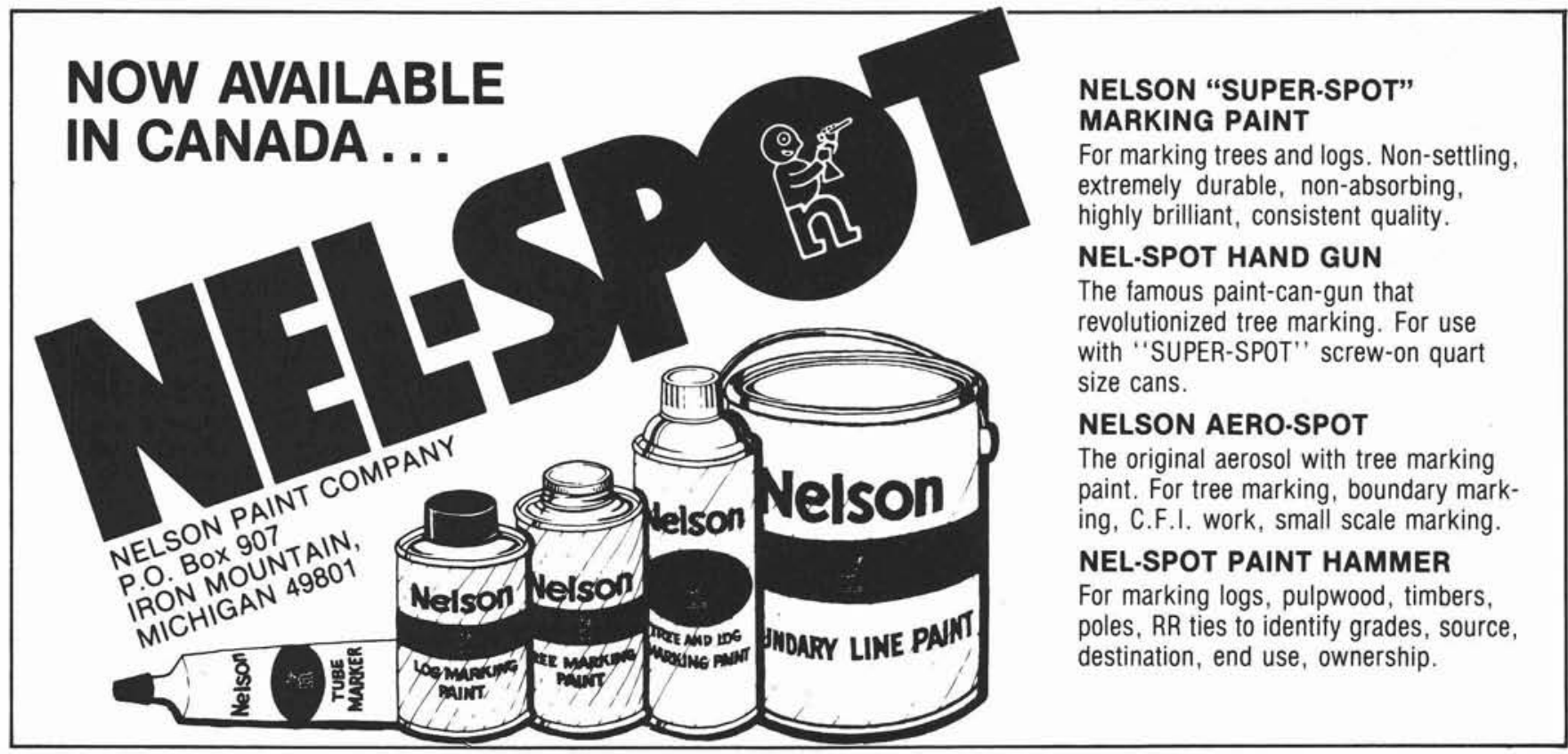

\section{FOREST TREE SEED FOR SALE}

Forest tree seedlots are available for sale for the following species:

\section{White Spruce \\ Red Spruce \\ Spruce hybrids \\ Jack Pine \\ Eastern White Pine \\ Eastern Larch \\ Japanese Larch}

Quantities vary from 45-1,735 pounds per lot.

If interested, please contact J.D. Irving Limited,

Sussex Tree Nursery, R.R. \#4, Aiton Road, Sussex,

New Brunswick, Canada EOE 1PO. Phone: (506) 433-4253.

\section{Woodlot Service (1978) Ltd.}

"All Matters PertalnIng to Forestry"

\section{GORDON B. YOUNG, B.Sc.F., M.F.}

Registered Professional Forester

320 Maple Street

Fredericton, N.B.

Bus.: 506-458-9366

E3A $3 B 4$ 